\title{
Investigation of the Physical Activity Self-Worth of Women Who Study in University
}

\author{
${\text { Yakup Kılıç }{ }^{1, *} \text { \& Eyyup Yıldırım }}^{1}$ \\ ${ }^{1}$ Faculty of Sports Sciences, Frrat University, Elazığ, Turkey \\ *Correspondence: Faculty of Sports Sciences, Firat University, Elazığ, Turkey. Tel: 90-532-343-8718. E-mail: \\ yakupkilic@firat.edu.tr
}

Received: January 6, 2020

Accepted: February 12, 2020 Online Published: February 19, 2020

doi:10.5430/wje.v10n1p110

URL: https://doi.org/10.5430/wje.v10n1p110

\begin{abstract}
This study was conducted with the aim of investigating the physical activity self-worth of women who study in university. To measure the physical activity self-worth of the participants, the "Physical Activity Self-Worth Inventory", which was developed by Huberty et al. (2013), was employed. As a result of the data obtained, "Independent samples t-test", which is one of the parametric tests, was conducted to evaluate the level of differentiation in the variable of gender, an independent variable. To determine the differences in the answers provided for the question, "Are there any physical activities that you do for at least half an hour or longer in a week?' and the variable of grade, "One-Way Variance Analysis" was conducted, which is one of the parametric tests. The level of statistical significance ( $\alpha$ error level) was regarded as $p<0.05$. According to the faculties where the participants studied, it was determined that there were statistically significant differences in terms of the scores of physical activity knowledge subscale, physical activity emotional subscale and the total scores of physical activity self-worth inventory $(\mathrm{p}<0.05)$. According to the participation of the participants in physical activities, it was determined that there were statistically significant differences in terms of the scores of physical activity knowledge subscale, physical activity emotion subscale and the total scores of physical activity self-worth inventory ( $<0.05$ ). According to the grade at which the participants studied, it was determined that there were no statistically significant differences in terms of the total scores of physical activity self-worth inventory and all of its subscales ( $p>0.05)$. In conclusion, in the comparison of the students of the faculty of sports sciences to the students of other departments, it was observed that the physical activity self-worth scores of those who exercise at least half an hour were higher compared to those who exercise irregularly and those who never exercise. Accordingly, the contents of elective lessons that can increase participation in physical activities in other departments of universities should be increased. To increase the individuals' time and frequency of participation in physical activities, informative education that includes the benefits of physical activity to general health should be conducted.
\end{abstract}

Keywords: physical activity, university, women

\section{Introduction}

Physical activity is not only a sporting activity but also a state of activity that individuals can conduct anywhere, from their workplace to their habitat, including the institution where they study (Ayhan, 2014). Physical activity is the totality of deliberate movements that is produced as a result of contractions of skeletal muscles while requiring energy consumption at above the basal level, increasing heart and respiratory rates at various aerobic and anaerobic intensities, which increases energy consumption (Isik et al., 2015; Ozer, 2010; Baltaci, 2008). Individuals who regularly participate in physical activities have higher physical capacities compared to sedentary individuals (Alpkaya et al., 2004).

Physical activity is important in people's lives in terms of a healthy life. As the workforce decreased with the developed technology, the time for people to sit at homes and workplaces increased, which led to adopting a sedentary lifestyle (Norman, 1999). This brought along various health problems and become a significant public health concern due to its negative effects on human health (Thompson et al., 2010). Therefore, as individuals got older and health problems increased, physical activity became a necessity (Sanli \& Atalay, 2009). 
In previous years, it was observed that the insufficiency of participation in physical activities became widespread in adult and elderly populations. The limited participation of individuals in physical activity has many reasons, including physical, psychological and behavioral reasons. One of the most common reasons for individuals to hinder participation in physical activities in Turkey is the limited time of individuals (Ozturk, 2005; Ayhan et al., 2018).

In studies conducted on the frequency of participating in physical activities, attitude toward and satisfaction from physical activity, it was concluded that participation rather varied depending on the age of individuals (Anderssen et al., 2005; Ayhan et al., 2018). The period when this is the most apparent is the ages of university education (Irwin, 2004; Anderssen et al., 2005). This period is of vital importance in terms of participating in and maintaining regular physical activity.

In the social environment, especially women adopted a sedentary lifestyle by avoiding exercise. A sedentary lifestyle has significant negative effects in terms of women's health. It is known that women experience more obstacles in terms of time compared to men (Soyer et al., 2017; Akdur, 2003). The fact that women have more responsibilities in domestic and social terms leads them to experience problems in terms of time and participate in activities less compared to men (Ayhan et al., 2017). As it is valid for all the individuals in the society, it is vitally important to conduct physical activities regularly for women as well. Today, the participation of women in physical activities has greatly increased thanks to creating new opportunities for women, putting legal regulations for women into effect and the increased number of medical and physical suitability studies on this subject (Koca \& Bulgu, 2005). Within this scope, in the literature review, it was observed that there were a limited number of studies on determining the physical activity self-worth of women for them to conduct healthier lives. The study conducted within this framework aimed to investigate the physical activity self-worth in female students who studied at the university level.

\section{Method}

\subsection{Aim of the Study}

The aim of this study is to investigate the physical activity self-worth perceptions of women who studied at the university level.

\subsection{Participants of the Study}

The sample of the study consisted of 329 randomly chosen female students who studied at the faculty of sports sciences (107 students from the department of physical education and sports teaching, the department of coaching education and the department of sports management) and the faculty of health sciences (222 students from the department of midwifery, the department of nursery, the department of nutrition and dietetics and the department of physiotherapy and rehabilitation) in Firat University. The reason for creating the sample of the study from these two faculties was convenience and the knowledge of the students in the field of health.

\subsection{Data Collection Tools}

Within the scope of the study, to collect data from the sample group, the "Women's Physical Activity Self-Worth Inventory" was adopted. The scale was developed by Huberty et al. (2013) and included 37 items within 3 subscales. The 37 items of the scale, which measures the non-physical aspects of physical activity self-worth in women, are measured by a 4-point Likert- type scale (strongly disagree [1], disagree [2], agree [3], and strongly agree [4]). The Cronbach alpha coefficients for the subscales of the scale were $0.90,0.87$ and 0.75 for the subscales of physical activity knowledge self-worth, physical activity emotional self-worth and physical activity social self-worth, respectively. As the scores increase, the feeling of self-worth also increases. The adaptation study of the scale into Turkish was conducted by Yurtcicek (2014). In the study, she conducted content and construct validity studies. To determine the reliability of the scale, internal consistency and item analysis techniques were employed. In the item analysis of the scale, it was determined that the highest correlation was in item $26(\mathrm{r}=0.608)$ while the lowest correlation was item $34(\mathrm{r}=0.155)$. The split-half reliability of the scale was determined as 0.74 while the Cronbach alpha coefficient for the totality of the scale was determined as 0.91 , which was followed by 0.90 in the "Physical Activity Knowledge Subscale (16 items)", 0.86 in the "Physical Activity Emotional Subscale (13 items)" and 0.80 in the "Physical Activity Social Subscale (8 items)". As a result of the reliability analyses, the internal consistency and

item analyses of the Women's Physical Activity Self-Worth Inventory were evaluated, and it was determined the scale was highly reliable. 


\subsection{Data Analysis}

For the data obtained from 329 students, a normality test was conducted to determine whether the "Women's Physical Activity Self-Worth Inventory" and its subscales provided a normality assumption, and it was observed that the data provided the normality assumption. Then, to reveal the distributions of the sample in terms of individual variables, frequency and percentage calculations were conducted. "Independent samples t-test", which is one of the parametric tests, was conducted to evaluate the level of differentiation in the variable of gender, an independent variable. To determine the differences in the answers provided for the question, "Are there any physical activities that you do for at least half an hour or longer in a week?" and the variable of grade, "One-Way Variance Analysis" was conducted, which is one of the parametric tests. The level of statistical significance (alpha $[\alpha]$ error level) was regarded as $\mathrm{p}<0.05$. LSD test was conducted to reveal the differences between variables.

\section{Findings}

In this section, the findings obtained from the sample group, according to the aims of the study, were presented.

Table 1. T-test Results of the Sample Group According to the Faculties Where They Studied

\begin{tabular}{lllllll}
\hline Scale & Faculty & $\mathrm{N}$ & $\overline{\mathrm{X}}$ & $\mathrm{Sd}$ & $\mathrm{t}$-value & $\mathrm{p}$-value \\
\hline Women's Physical Activity & Faculty of Sports Sciences & 107 & 3.214 & 0.386 & 4.785 & $0.000^{*}$ \\
Self-Worth Inventory & Faculty of Health Sciences & 222 & 2.970 & 0.453 & & \\
Physical Activity Knowledge & Faculty of Sports Sciences & 107 & 3.439 & 0.445 & 5.402 & $0.000^{*}$ \\
Subscale & Faculty of Health Sciences & 222 & 3.130 & 0.503 & & $0.000^{*}$ \\
Physical Activity Emotion & Faculty of Sports Sciences & 107 & 3.294 & 0.452 & 5.945 & \\
Subscale & Faculty of Health Sciences & 222 & 2.957 & 0.494 & & 0.630 \\
Physical Activity Social & Faculty of Sports Sciences & 107 & 2.634 & 0.612 & -0.482 & \\
Subscale & Faculty of Health Sciences & 222 & 2.670 & 0.637 & &
\end{tabular}

When the results of the analyses were evaluated (Table 1), it was determined that there were statistically significant differences in the faculty status of the participants in terms of the scores of physical activity knowledge, physical activity emotion, and the total scores of physical activity self-worth inventory $(\mathrm{p}<0.05)$. Additionally, the students of the faculty of sports sciences had higher physical activity self-worth scores in all of the scales, except for the physical activity social subscale, compared to the students of the faculty of health sciences. According to the status of the faculty where the participants studied, no statistically significant differences were observed in the physical activity social subscale of the physical activity self-worth inventory $(\mathrm{p}>0.05)$.

When the results of the analyses were evaluated (Table 2), it was determined that there were statistically significant differences in the participation in physical activity status of the participants in terms of the scores of physical activity knowledge, physical activity emotion, and the total scores of physical activity self-worth inventory $(\mathrm{p}<0.05)$. Additionally, the students who did physical activities regularly had higher physical activity self-worth scores in all of the scales, except for the physical activity social subscale, compared to the students who did not do physical activities regularly or did physical activities irregularly. According to the status of participation in physical activities, no statistically significant differences were observed in the physical activity social subscale of the physical activity self-worth inventory $(\mathrm{p}>0.05)$. 
Table 2. One-way Variance Results of the Answers of the Participants to the Question "Are There Any Physical Activities that You Do for at Least Half an Hour or Longer in a Week?"

\begin{tabular}{|c|c|c|c|c|c|c|c|}
\hline Scale & $\begin{array}{l}\text { Status of Doing Physical } \\
\text { Activity }\end{array}$ & $\mathrm{N}$ & $\bar{X}$ & $\mathrm{Sd}$ & $\mathrm{F}$ & p-value & LSD \\
\hline \multirow{3}{*}{$\begin{array}{l}\text { Women's Physical Activity } \\
\text { Self-Worth Inventory }\end{array}$} & (a) Yes & 126 & 3.126 & 0.430 & \multirow{3}{*}{5.267} & \multirow{3}{*}{$0.006^{*}$} & $\mathrm{a}, \mathrm{b}$ \\
\hline & (b) No & 70 & 2.913 & 0.482 & & & \multirow[t]{2}{*}{$\mathrm{b}, \mathrm{c}$} \\
\hline & $\begin{array}{l}\text { (c) Irregular (unknown } \\
\text { frequency) }\end{array}$ & 133 & 3.048 & 0.429 & & & \\
\hline \multirow{3}{*}{$\begin{array}{l}\text { Physical Activity Knowledge } \\
\text { Subscale }\end{array}$} & (a) Yes & 126 & 3.353 & 0.511 & \multirow{3}{*}{8.246} & \multirow{3}{*}{$0.000^{*}$} & $\mathrm{a}, \mathrm{b}$ \\
\hline & (b) No & 70 & 3.059 & 0.515 & & & $\mathrm{a}, \mathrm{c}$ \\
\hline & $\begin{array}{l}\text { (c) Irregular (unknown } \\
\text { frequency) }\end{array}$ & 133 & 3.205 & 0.466 & & & $\mathrm{~b}, \mathrm{c}$ \\
\hline \multirow{3}{*}{$\begin{array}{l}\text { Physical Activity Emotion } \\
\text { Subscale }\end{array}$} & (a) Yes & 126 & 3.188 & 0.498 & \multirow{3}{*}{11.173} & \multirow{3}{*}{$0.000^{*}$} & $\mathrm{a}, \mathrm{b}$ \\
\hline & (b) No & 70 & 2.842 & 0.516 & & & $\mathrm{~b}, \mathrm{a}$ \\
\hline & $\begin{array}{l}\text { (c) Irregular (unknown } \\
\text { frequency) }\end{array}$ & 133 & 3.069 & 0.469 & & & $\mathrm{~b}, \mathrm{c}$ \\
\hline \multirow{3}{*}{$\begin{array}{l}\text { Physical } \\
\text { Subscale }\end{array}$} & (a) Yes & 126 & 2.572 & 0.644 & \multirow{3}{*}{1.988} & \multirow{3}{*}{0.139} & \multirow{3}{*}{-} \\
\hline & (b) No & 70 & 2.733 & 0.616 & & & \\
\hline & $\begin{array}{l}\text { (c) Irregular (unknown } \\
\text { frequency) }\end{array}$ & 133 & 2.700 & 0.615 & & & \\
\hline
\end{tabular}

$* \mathrm{p}<0.05$

Table 3. One-way Variance Analysis Results of the Sample Group According to the Grade at Which They Studied

\begin{tabular}{lllllll}
\hline Scale & Grade & $\mathrm{N}$ & $\overline{\mathrm{X}}$ & $\mathrm{Sd}$ & $\mathrm{F}$ & $\mathrm{p}$-value \\
\hline & (a) $1^{\text {st }}$ Grade & 113 & 3.039 & 0.475 & & \\
Women's Physical Activity & (b) $2^{\text {nd }}$ Grade & 94 & 3.071 & 0.492 & \multirow{2}{*}{0.377} & 0.770 \\
Self-Worth Inventory & (c) $3^{\text {rd }}$ Grade & 80 & 3.015 & 0.399 & & \\
& (d) $4^{\text {th }}$ Grade & 42 & 3.093 & 0.344 & & \\
& (a) $1^{\text {st }}$ Grade & 113 & 3.234 & 0.549 & & \\
Physical Activity Knowledge & (b) $2^{\text {nd }}$ Grade & 94 & 3.221 & 0.530 & \multirow{2}{*}{0.212} & \multirow{2}{*}{0.888} \\
Subscale & (c) $3^{\text {rd }}$ Grade & 80 & 3.210 & 0.445 & & \\
& (d) $4^{\text {th }}$ Grade & 42 & 3.284 & 0.437 & & \\
Physical Activity Emotion Subscale & (a) $1^{\text {st }}$ Grade & 113 & 3.027 & 0.512 & & \\
& (b) $2^{\text {nd }}$ Grade & 94 & 3.105 & 0.564 & \multirow{2}{*}{0.933} & 0.425 \\
& (c) $3^{\text {rd }}$ Grade & 80 & 3.032 & 0.463 & & \\
& (d) $4^{\text {th }}$ Grade & 42 & 3.152 & 0.420 & & \\
Physical Activity Social Subscale & (a) $1^{\text {st }}$ Grade & 113 & 2.668 & 0.686 & & \\
& (b) $2^{\text {nd }}$ Grade & 94 & 2.715 & 0.637 & \multirow{2}{*}{0.588} & 0.643 \\
& (c) $3^{\text {rd }}$ Grade & 80 & 2.600 & 0.583 & & \\
& (d) $4^{\text {th }}$ Grade & 42 & 2.616 & 0.531 & &
\end{tabular}

$* \mathrm{p}<0.05$ 
When the results of the analyses were evaluated (Table 3), it was determined that there were no statistically significant differences in the grade levels of the participants in terms of the total scores of physical activity self-worth inventory and all of its subscales ( $p>0.05$ ). Additionally, it was observed that the physical activity self-worth scores of all of the participants were rather similar to each other, regardless of the grade level.

\section{Discussion and Conclusion}

In this study, it was aimed to investigate the physical activity self-worth of women who studied at the university level. The findings obtained within the scope of this aim were interpreted and presented in this section.

When the results of the analyses were evaluated, it was determined there were statistically significant differences in the physical activity knowledge and physical activity emotion subscales of the women's physical activity self-worth inventory and the total scores of the physical activity self-worth inventory according to the types of faculties at which the participants studied. Accordingly, it was revealed that the physical activity self-worth scores of women who studied at the faculty of sports sciences were higher compared to the scores of women who studied at the faculty of health sciences. The related literature also included studies that supported these conclusions (Savci et al., 2006; Sahin et al., 2017). It is believed that this can be due to the fact that the students of the faculty of sports sciences are constantly connected to physical activities thanks to the departments where they study.

When the results of the analyses were evaluated, it was also determined that there were statistically significant differences in the physical activity knowledge and physical activity emotional subscales of the women's physical activity self-worth inventory and the total scores of the women's physical activity self-worth inventory according to the status of participating in physical activity for at least half an hour and longer. It was further determined that the physical activity self-worth values of women who participated in physical activities were higher compared to those who irregularly participate in physical activities or those who do not participate in physical activities. Accordingly, in the evaluation of physical activity self-worth total scores, it was concluded that there were differences between the physical activity self-worth scores of women who participated in physical activities and women who irregularly participated in physical activities. When the physical activity knowledge subscale was evaluated, it was observed that there were statistically significant differences between the mean scores of women who participated in physical activity and those who did not participate in physical activity and those who irregularly participated in physical activities. It was also observed that there were differences between the mean scores of women who irregularly participated in physical activities and women who did not participate in physical activities. Additionally, when the physical activity emotional subscale was evaluated, it was concluded that there were statistically significant differences between the mean physical activity emotion scores of women who participated in physical activities, who irregularly participated in physical activities and women who did not participate in physical activities. It is expected that individuals who participate in physical activities for at least 30 minutes have higher physical activity self-worth values. This is believed to be due to the fact that the participation of individuals in physical activity for at least 30 minutes and longer serves the purpose of preserving their general health. The related literature includes studies that support these conclusions. For example, Pate et al. (1995) reported that the physical activities done for at least 30 minutes had vital importance to preserve general health. This notion was also supported by the study of Driskell et al., who suggested that physical activities should be conducted every day or most days of the week for at least 30 minutes to provide benefits in terms of health (Driskell et al., 2005). Crespo et al. (2002) noted that moderate-intensity regular physical activities had positive effects on the development of the skeletal muscle system. Rikli (2005) reported that participation in physical activities at every age had a significance in terms of general health.

When the results of the analyses were evaluated, it was determined that there were no statistically significant differences in all of the subscales of the women's physical activity self-worth inventory and the total scores of women's physical activity self-worth inventory according to the grade level at which the participants studied.

The limitation of the study included the sample size, gender, and population of the study. In our study, only the students of the faculty of sports sciences and the students of the faculty of health sciences were included in the sample group, which limited the generalization of the results of the study. In future studies, the sample size can be increased by including other faculties with different aims and aspects. The sample can also be formed from individuals who are assumed both to be involved and not to be involved in physical activities. In terms of the gender aspect, new measurement and data collection tools that can cover both males and females can be developed to enable a larger point of view while investigating physical activity self-worth.

In conclusion, in the comparison of the students of the faculty of sports sciences to the students of other departments, 
it was observed that the physical activity self-worth scores of those who exercise at least half an hour were higher compared to those who exercise irregularly and those who never exercise. Accordingly, the contents of elective lessons that can increase participation in physical activities in other departments of universities should be increased. To increase the individuals' time and frequency of participation in physical activities, informative education that includes the benefits of physical activity to general health should be conducted.

\section{References}

Akdur, H. (2003). To research the physical activity levels of housewives and women who work. Istanbul University Journal of Sport Sciences, 11(3), 43-46.

Alpkaya, U., \& Mengutay, S. (2004). An investigation on effects of physical activity to reaction time. Gazi Journal of Physical Education and Sports Sciences, 9(3), 49-57.

Anderssen, N., Wold, B., \& Torsheim, T. (2005). Tracking of Physical Activity in Adolescence. Research Quarterly for Exercise and Sport, 76(2), 119-129.

Ayhan, C., Ekinci, N., Yalcin, I., \& Yigit, S. (2018). Investigation of constraints that occur during participation in leisure activities by high school students: a sample of Turkey. Education Sciences, 8(2), 86. https://doi.org/10.3390/educsci8020086

Ayhan, C., Eskiler, E., \& Ekinci, N. E. (2018). Extreme Sporcularin Serbest Zaman Tatmin Duzeylerinin Cesitli Degiskenler Acisindan Incelenmesi (translation: Investigation of Leisure Time Satisfaction Levels of Extreme Athletes in terms of Different Variables). 2nd International Academic Sport Research Congress, 125-132.

Ayhan, C., Eskiler, E., \& Soyer, F. (2017). Aktif sporcularin rekreatif etkinliklere katilimlarina engel olusturabilecek faktorlerin yasam tatmini ve yasam kalitesi uzerine etkisi (translation: Effects of factors that can prevent active athletes to participate in recreational activities on satisfaction of life and quality of life). ERPA International Congresses on Education, Book of Proceedings, 164-175.

Ayhan, Y. F. (2014). The examining of the physical activity practices during childhood and adolescence along with physical activity level and body composition during adulthood. Master Thesis, Mugla Sitki Kocman University. Health Sciences Institute, Mugla

Baltaci, G. (2008). Cocuk ve Spor (translation: Children and Sports) (1. Printing). Ankara: Klasmat Printing. (ISBN: 978-975-590-246-3)

Crespo, C. J., Palmieri, M. R. G., Perdomo, R. P., Mcgee, D. L., Smit, E., Sempos, C. T., Lee, I. M., \& Sorlie, P. D. (2002). The relationship of physical activity and body weight with all-cause mortality: results from the Puerto Rico heart health program. Annual Epidemiology, 12(8), 543-552. https://doi.org/10.1016/S1047-2797(01)00296-4

Driskell, J. A., Kim, Y. N., \& Goebel, K. J. (2005). Few differences found in the typical eating and physical activity habits of lower-level and upper-level university students. Journal of the American dietetic association, 105(5), 798-801. https://doi.org/10.1006/pmed.1998.0375

Huberty, J., Vener, J., Gao, Y., Matthews, L. J., Ransdell, L., \& Elavsky, S. (2013). Developing an instrument to measure physical activity related self-worth in women: Rasch analysis of the women's physical activity self-worth inventory (WPASWI). Psychology of Sport and Exercise, 14(1), 111-121. https://doi.org/10.1016/j.psychsport.2012.07.009

Irwin, J. D. (2004). Prevalence of university students' sufficient physical activity: a systematic review. Perceptual and Motor Skills, 98, 927-943. https://doi.org/10.2466/pms.98.3.927-943

Koca, C., \& Bulgu, N. (2005). Spor ve toplumsal cinsiyet: genel bir bakis (translation: Sports and social gender: a general view). Society and Science, 103, 163-184.

Norman, G. R. C. (1999). Stage of change, leisure time physical activities, and fitness level in adolescents, the degree of doctor of philosophy, Northwest Missouri State University, (ProQuest Online Database UMI No: 9932763, 11/05/2005).

Olcucu, B., Vatansever, S., Ozcan, G., Celik, A., \& Paktas, Y. (2015). The relationship between depression, anxiety and physical activity level among university students. International Journal of Turkish Education Sciences, 3(4), 294-303. 
Ozer, K. (2010). Fiziksel uygunluk (translation: Physical fitness). Ankara: Nobel Publication Distribution.

Ozkan, I., Ozarslan, A., \& Bekler, F. (2015). The correlation among physical activity, quality of sleep and depression among the university students. Journal of Physical Education and Sports Sciences, 9.

Ozturk, M. (2005). A research on reliability and validity of international physical activity questionnaire and determination of physical activity level in university students. Master Thesis, Hacettepe University Institute of Health Sciences.

Pate, R. R., Pratt, M., Blair, S. N., Haskell, W. L., Macera, C. A., Bouchard, C., Buchner D., Ettinger, W., Heath, G. W.,... King, A. C. (1995). Physical activity and public health: a recommendation from the Centers for Disease Control and Prevention and the American College of Sports Medicine. JAMA, 273(5), 402-407. https://doi.org/10.1001/jama.273.5.402

Rikli, R. E. (2005). Movement and mobility influence on successful aging: addressing the issue of low physical activity. QUEST, 57, 46-66. https://doi.org/10.1080/00336297.2005.10491842

Sahin, M., Kirandi, O., AtabaS, G., \& Bayraktar, B. (2017). Physical Activity Levels of Students in Faculty of Sport Sciences (Istanbul University Example). Journal of Sport Education, 1(1), 26-33.

Sanli, E., \& Atalay, N. A. (2009). Physical activity levels of the teachers and relation between age, gender and body mass index Gazi. Journal of Physical Education and Sports Sciences, 14(3), 23-32.

Savci, S., Ozturk, M., Arikan, H., Ince, I. D., \& Tokgozoglu, L. (2006). Physical activity levels of university students. Turkish Cardiology Association Archive, 34(3), 166-172.

Soyer, F., Yildiz, N. O., Harmandar, D., Serdar, E., Demirel, M., Ayhan, C., \& Demirhan, O. (2017). The investigation of the relationship between the factors that prevent university students from attending to the recreational activities and the life satisfaction of the participants. Journal of Human Sciences, 14(2), 2035-2046. https://doi.org/10.14687/jhs.v14i2.4647

Thompson, W. R., Gordon, N. F., \& Pescatello, L. S. (2010). ACSM's guidelines for exercise testing and prescription. American College of Sports Medicine. 8th ed. Baltimore (MD): Lippincott Williams \& Wilkins, p. 400. (ISBN: $9780781769020078176902797807817690370781769035)$

Yurtcicek, S. (2014). The study of the validity and reliability of the Turkish version of women's physical activity self-worth inventory. Master Thesis, Marmara University, Institute of Health Sciences, Istanbul. 